\title{
VIABILIDADE DE SEMENTES DE ACEROLA (Malpighia emarginata DC): AVALIAÇÃO DA VITALIDADE DOS TECIDOS ${ }^{1}$
}

\author{
LUCIANA CLAUDIA COSTA²; MARIA DO CARMO MORELLI DAMASCENO PAVANI ${ }^{3}$; FABÍOLA VITTI MORO; \\ DILERMANDO PERECIN ${ }^{4}$
}

\begin{abstract}
RESUMO - A morfologia interna e a viabilidade de sementes de acerola (Malpighia emarginata DC.) foram estudadas utilizando-se o tetrazólio (cloreto de 2, 3, 5 trifenil tetrazólio). Dos clones testados, o Flórida Sweet foi o que apresentou a menor percentagem de sementes com embriões normais (10\%) como também em reação às sementes sem embriões $(8 \%)$ e o maior percentagem de sementes com embriões deformados (81\%). O clone 07-OS apresentou maior percentagem de sementes com embriões normais (51\%) e um número considerado elevado de sementes sem embriões (34\%). Os demais clones apresentaram valores intermediários. Para todos os clones avaliados, as sementes com embriões normais apresentaram $100 \%$ de embriões viáveis. Essas sementes submetidas ao teste de tetrazólio por um período de 12 horas, apresentaram-se com uma coloração vermelha intensa, considerada ideal para a avaliação positiva da viabilidade das sementes. Estes resultados não podem, entretanto, ser tomados para prognóstico e o cálculo da taxa de germinação e dormência, apenas indicando que as sementes estão vivas.
\end{abstract}

Termos de Indexação: Acerola (Malpighia emarginata DC.), teste tetrazólio, sementes vivas e embriões.

\section{SEED VIABILITY OF ACEROLA (Malpighia emarginata DC.): EVALUATION OF THE TISSUE VITALITY}

ABSTRACT - The morphology and seed viability of acerola (Malpighia emarginata DC.) were evaluated using the tetrazolium (2, 3, 5 triphenyl tetrazolium chloride). From all clones tested, Florida Sweet presented the smallest percentage of seeds with normal embryos (10\%) or without them $(8 \%)$ and the greatest percentage of seeds with malformed embryos, $(81 \%)$. The clone $07-0 \mathrm{~S}$ had the greatest percentage of seeds with normal embryos (5 1\%) and an elevated number of seeds without embryos (34\%). For all other clones evaluated, the seeds with normal embryos were

$100 \%$ viable. The seeds subjected to the tetrazolium test for 12 hours, had a deep red color, considered

ideal for viability positive evaluation. These tests cannot be taken as prognosis to calculate the germination and dormancy rates, only indicating that the seeds are alive.

Key words: Malpighia emarginata DC., tetrazoilium test, seeds alive, embryos.

O fruto da acerola (Malpighia emarginata DC.) é uma baga drupácea que apresenta três sementes, cada uma envolvida por um endocarpo reticulado e trilobado.

As sementes são pequenas, não albuminadas e de tamanhos variáveis, proporcionais ao tamanho do fruto e, consequentemente, ao do "caroço". Essas sementes apresentam baixa porcentagem de germinação, podendo ainda, dependendo do grau de maturação do fruto, levar meses para que germinem, sendo comum a ocorrência de sementes inviáveis, em relação à futura germinação. Isso porque dos três óvulos existentes, apenas um ou dois se desenvolvem em decorrência de fatores como a má formação do óvulo, a degeneração do saco embrionário e a falta de fertilização do óvulo, dentre outros, que resultam na baixa germinação.

Lendim (1998), citado por Gomes (2001), constatou que sementes de acerola que germinam com facilidade podem originar plantas cujos frutos produzem sementes inviáveis, com germinação frequentemente inferior a $50 \%$. Dentre os testes considerados rápidos para a avaliação da qualidade das sementes, o do tetrazólio possibilita a avaliação da viabilidade (probabilidade do zigoto se desenvolver e atingir o estádio adulto) e do vigor das sementes.

Para Botezelti (1998), o teste com tetrazólio é classificado como indireto na avaliação dessa viabilidade e rápido na estimativa antecipada da germinação, apresentando excelentes condições para aplicação de rotina, principalmente para espécies de tempo de germinação excessiva.

Assim, várias pesquisas têm sido desenvolvidas procurando a obtenção precoce dos resultados de viabilidade, bem como a padronização do teste de tetrazólio para cada uma das espécie estudadas.

Nesse trabalho, conduzido na Faculdade de Ciências Agrárias e Veterinárias, UNESP, Câmpus de Jaboticabal, foram avaliados 100 fru- tos maduros, recém-colhidos de cada clone (CL-5, CL-11, R1, Olivier, Flórida Sweet, 07-OS, I-7 e V-13), totalizando 2400 sementes.

Preliminarmente foram realizados testes com soluções de tetrazólio a $0,1 \%$ e $0,5 \%$ e sementes com embriões normais do clone Olivier que ficaram embebidas em tetrazólio por períodos de 2 à 12 horas. A embebição na concentração de $0,5 \%$ por 12 horas foi a que apresentou a melhor capacidade e uniformidade de coloração.

Após os testes preliminares, 300 sementes de cada um dos clones foram deixadas embeber em água, à temperatura ambiente $\left(25^{\circ} \mathrm{C}\right)$, por aproximadamente 9 horas, para permitir uma maior facilidade de corte das sementes, o que, segundo Krzyzanowski et al. (1999), não só facilita o corte das sementes como também acelera o seu metabolismo, proporcionando uma coloração mais nítida. Após a embebição, as sementes foram enxugadas em papel toalha, cortadas no sentido longitudinal com o auxílio de uma lâmina de bisturi, e avaliadas em relação ao número de sementes com embriões normais, sementes com embriões deformados e sementes sem embriões, sendo esses resultados expressos, também, pelos respectivos percentuais.

As sementes com embriões normais foram colocadas em recipientes de $50 \mathrm{~mL}$, e totalmente imersas em soluções de 2, 3, 5 trifenil cloreto de tetrazólio $(\mathrm{pH}=7,0)$, concentração de $0,5 \%$, por 6 períodos $(2,4,6,8$, 10 e 12 horas), e a $25^{\circ} \mathrm{C}$, na ausência de luz. Após cada período de tempo foi feita uma avaliação visual da coloração, entretanto, apenas depois de um período de 12 horas, as sementes com embriões normais apresentaram a melhor definição de coloração, sendo que esta foi baseada no aspecto dos tecidos e na intensidade e uniformidade de coloração. Para percentagem de sementes com embriões normais foi estimado o erro padrão esperado, pela seguinte fórmula [ $p(1-p) / 300]$ ? x 100, onde p é a proporção observada de sementes com embriões normais. Essas sementes não foram avaliadas em relação à germinação, propriamente dita.

${ }^{1}$ (Trabalho 176/2002). Recebido: 05/12/2002. Aceito para publicação: 11/09/2003.

${ }^{2}$ Bióloga M. Sc. Doutora em Agronomia - Genética e Melhoramento de Plantas. Manaus - AM. CEP: 69040.280. Email: lcynone@bol.com.br. Telefone (92) 656 4635 .

${ }^{3}$ Eng. Agrônoma, Prof. Dra. do Departamento de Biologia Aplicada FCAV-UNESP-Jaboticabal - SP. CEP: 14870.000. Email: mcarmo@fcav.unesp.br e fabíola@fcav.unesp.br.Telefone (16) 3209-2620.

${ }^{4}$ Eng. Agrônomo, Prof. Dr. do Departamento de Ciências Exatas FCAV-UNESP-Jaboticabal-SP. CEP: 14870.000. Email: perecin@fcav.unesp.br .Telefone (16) 3209 -2625 . 
TABELA 01 - Ocorrência de embriões normais, embriões deformados e de ausência de embriões nas sementes de acerola (percentagens em relação a 300 sementes; 3 sementes/fruto).

\begin{tabular}{|c|c|c|c|c|c|c|}
\hline \multirow[b]{2}{*}{ Clones } & \multicolumn{2}{|c|}{ Normais } & \multicolumn{2}{|c|}{ Deformados } & \multicolumn{2}{|c|}{ Ausência } \\
\hline & $\mathrm{n}^{\mathrm{o}}$ & $\%$ & $\mathrm{n}^{\mathrm{o}}$ & $\%$ & $\mathrm{n}^{\mathrm{o}}$ & $\%$ \\
\hline CL-5 & 95 & $31,67(2,68)^{*}$ & 146 & 48,66 & 59 & 19,67 \\
\hline CL-11 & 104 & $34,67(2,74)^{*}$ & 117 & 39,00 & 79 & 26,33 \\
\hline $\mathrm{R}-1$ & 67 & $22,33(2,40)^{*}$ & 149 & 49,67 & 54 & 28,00 \\
\hline Olivier & 148 & $49,33(2,88) *$ & 99 & 33,00 & 53 & 17,67 \\
\hline F.Sweet & 30 & $10,00(1,73)^{*}$ & 245 & 81,67 & 25 & 8,33 \\
\hline 07-OS & 154 & $51,33(2,88)^{*}$ & 43 & 14,34 & 103 & 34,33 \\
\hline I-7 & 123 & $41,00(2,84)^{*}$ & 142 & 47,33 & 35 & 11,67 \\
\hline $\mathrm{V}-13$ & 116 & $38,67(2,81)^{*}$ & 118 & 39,33 & 66 & 22,00 \\
\hline
\end{tabular}

*Erro padrão estimado $[\mathrm{p}(1-\mathrm{p}) / 300]^{1 / 2} \times 100$

A Tabela 01 mostra o número e percentagem de sementes de acerola com embriões normais, de sementes com embriões deformados e de sementes sem embriões, dos diferentes clones estudados. Desses clones, o Flórida Sweet apresentou o menor número de sementes com embriões normais e sementes sem embriões, 30 e 25 respectivamente $(10 \%$ e $8,33 \%)$ e o maior número de sementes com embriões deformados ( 245 sementes ou $81,67 \%$ ). O clone $07-O S$ apresentou o maior número de sementes com embriões normais ( 154 ou $51,33 \%$ ) como também um número alto de sementes sem embriões ( 103 ou $34,33 \%$ ). Os demais clones apresentaram valores intermediários aos valores limites anteriores. Esses resultados assemelham-se aos resultados em Símplicio et al. (1994) para sementes de acerola da cultivar Coopamai. Nessa cultivar, 29,36\% das sementes apresentaram embriões normais; $4,21 \%$, embriões deformados e $66,08 \%$, sem embriões, enquanto na cultivar Okinawa, essas percentagens foram, respectivamente, $5,81 \%, 19,32 \%$ e $74,34 \%$. Carvalho \& Possamai (1996), analisando frutos de acerolas, constataram que $27,21 \%$ deles apresentavam sementes normais em seu interior, $8,37 \%$ possuíam sementes deformadas, secas e enrugadas e $64,42 \%$ não possuíam sementes, ocorrências essas relacionadas à deficiência de polinização ou à incompatibilidade (mecanismo genético-fisiológico que tornam impossível ou extremamente difícil a fertilização), segundo Yamane

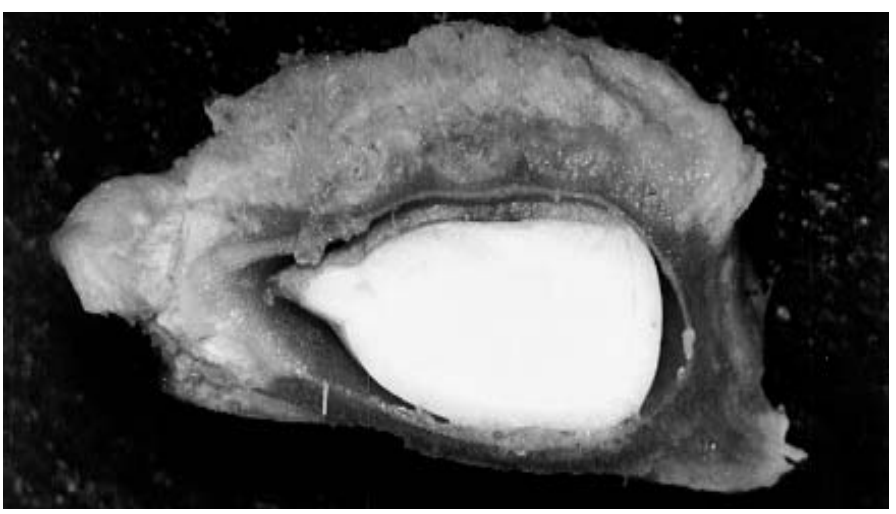

FIGURA01 - Vista do corte transversal da semente de acerola do clone Olivier com embrião íntegro e sem coloração (10 x).

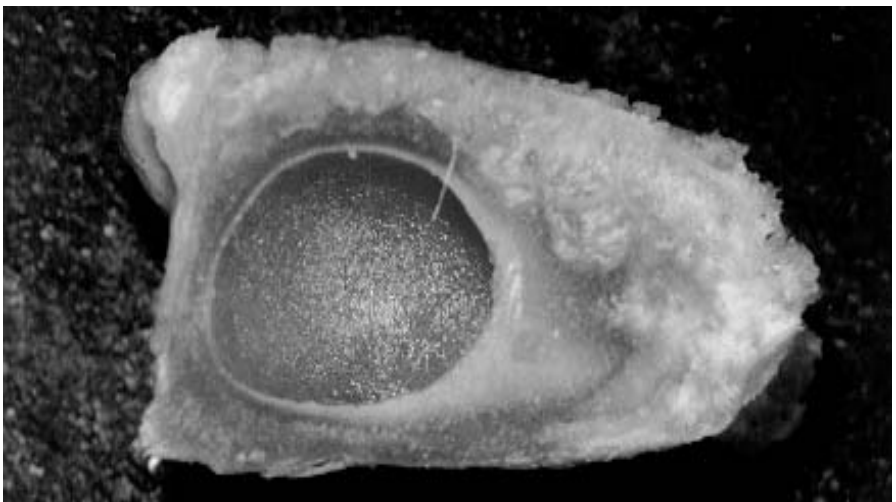

FIGURA 03 - Vista do corte transversal da semente de acerola do clone Olivier, onde a mesma apresenta-se sem embrião $(10 \mathrm{x})$.
\& Nakasone (1961) e Kumar et al (1981).

Em relação aos aspectos morfológicos internos as figuras de 01 a 03 mostraram sementes de acerola do clone Olivier com embriões normais, deformados e, algumas, sem embriões. Coincidentemente, as sementes com embriões considerados normais, submetidas ao teste com tetrazólio (Figura 04), resultaram em coloração interna e homogênea, típica de tecidos sadios, como preceituado por Malavasi et al. (2001). Essas características, entretanto, não devem servir para o prognóstico ou cálculo de indicadores de germinação, pois somente sugerem que os tecidos apresentam vitalidade suficiente à absorção celular de tetrazólio. Entretanto, pode-se concluir que os estudos dessa natureza demonstram a necessidade de testes complementares de eficiência de germinação ou de produção de mudas para que se possa relacionar a potencialidade de utilização aos parâmetros verificados; o número de embriões normais não deve ser considerado isoladamente uma vez que a presença simultânea de embriões normais e deformados pode indicar problemas na fisiologia das sementes. Tal preferência deve recair nas sementes que além de embriões bem formados (normais) apresentem, frente ao teste do tetrazólio, tecidos com coloração intensa e contrastes morfológicos bem definidos, indicadores de vitalidade.

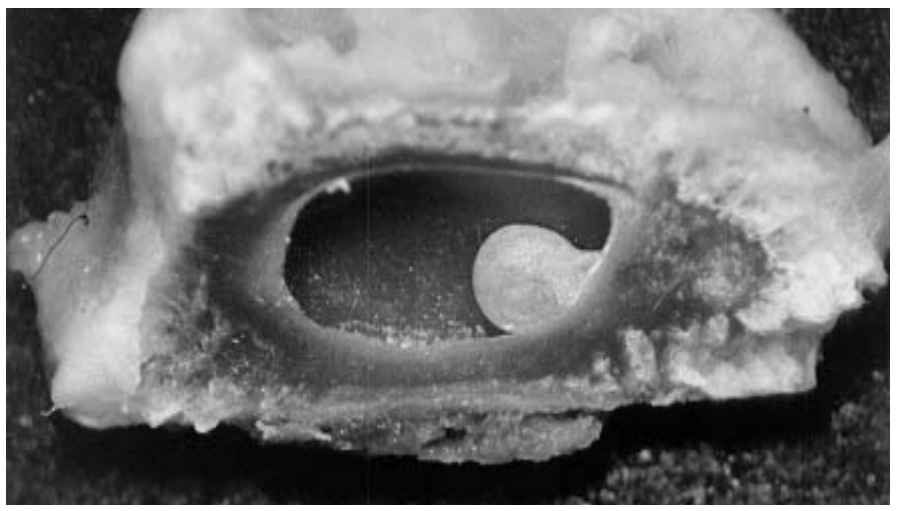

FIGURA 02 - Vista do corte transversal da semente de acerola do clone Olivier, onde a mesma apresenta embrião deformado $(10 \mathrm{x})$

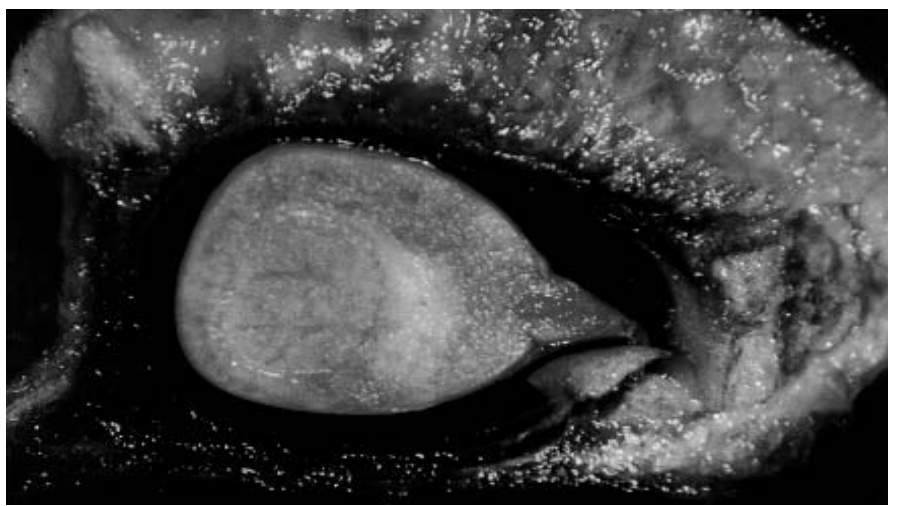

FIGURA 04 - Vista do corte transversal da semente de acerola do clone Olivier com embrião íntegro colorido a $0,5 \%$ no tetrazólio $(12 \mathrm{x})$. 


\section{AGRADECIMENTOS}

À FAPESP - Fundação de Amparo a Pesquisa no Estado de São Paulo, pela ajuda financeira fornecida durante este trabalho.

\section{REFERÊNCIASBIBLIOGRÁFICAS}

BOTEZELLI, L. Influência de ambientes e embalagens de armazenamento sobre a viabilidade e o vigor de sementes de baru (Dipterys alata Vorgel). 1998. 70 f. Dissertação (Mestrado em Fitotecnia) - Universidade Federal de Lavras, Lavras, MG., 1998.

CARVALHO, R. I. N. de, POSSAMAI, E. Avaliação de sementes com e sem caroços de acerola para produção de mudas. Inf. ABRATES, v.6, n. 2/3, p. 1996.

GOMES; J.E. Aspectos botânicos, físicos-químicos, genéticos e influências meteorológicas em aceroleiras (Malpighia emarginata DC.) no processo seletivo de genótipos de Itápolis, Viradouro e Jaboticabal, SP. Jaboticabal, 2001. 250f. Tese (Doutorado em Genética e Melhoramento de Plantas) - Faculdade de Ciências Agrária e
Veterinária, Universidade Estadual Paulista, Jaboticabal, 2001.

KRZYZANOWSKI, F. C.; VIEIRA, R. D. , FRANÇA NETO, J. B. Vigor de sementes : conceitos e testes. Londrina : ABRATES, 1999. 218 p.

KUMAR, R. S., PARTHASARATHY, V. H. , SUNDARAM, P. K. Cytological studies in the West Indian Cherry (Malpighia punicifolia L.). Progressive Horticulture, Chaubattia. v.13, n.2, p.73-76, 1981.

MALAVASI, M. M. et al. Preparo e coloração de sementes de maracujádoce (Passiflora alata Dryander) para avaliação da viabilidade através do teste de tetrazólio. Revista Brasileira de Fruticultura, Jaboticabal, v.23, n.1, p.126-129. 2001.

SÍMPLICIO, J. B; SILVA,A. K. S.; SOUZA JÚNIOR, U. S.; OKASAKI,W. Y.; MUSSER, R. S. Avaliação da presença de embrião sem sementes de duas seleções de acerola (Malpighia glabra L.) na zona da mata de Pernambuco. In: CONGRESSO BRASILEIRO DE FRUTICULTURA, 13., 1994, Salvador. Anais...p.81.

YAMANE, G. M.; NAKASONE, H. Y. Pollination and fruit set studies of acerola. Malpighia glabra L. In Hawaii. Proceedings of the American Society of Horticultural Science, Alexandria, v. 78, p. 141-48, 1961. 